\title{
Contribution to the measurement of stress level post stress management training
}

\author{
L C Dascalu ${ }^{1}$, O Chivu ${ }^{1}, \mathrm{C}$ Babiş $^{1}$, A Dimitrescu ${ }^{2}$ and E Niculae $^{2}$ \\ ${ }^{1}$ Welding and Material Technology Department, Politehnica University of Bucharest, Romania \\ ${ }^{2}$ Theory of Mechanisms and Robots Department, Politehnica University of Bucharest, \\ Romania \\ dascalu_loredana_cristina@yahoo.com
}

\begin{abstract}
The case study presented in this article consists in a questionnaire meant to detect stress in employees after a stress management training session. The study is a novelty because was elaborated on a group of employees after they learn one months about occupational stress management. Over the time, many of the studies conducted in the field of stress focus on a combination of the factors like this: reducting stress exposure and developing programes for physical exercises - relaxation and meditation. It is very important to have information about stress because it can change the perspective of life and the way in which we can see that a situasion can be negative or positive one.
\end{abstract}

Keywords: stress, questionnaires, occupational, measurement, management

\section{Introduction}

The purpose of this paper is to detect the stress level for a different fields of activity. I applied the following instrument: Cohen Williamson Questionnaire [1] to determine stress level. This study was conducted during the one month in Bucharest on a group of 30 employees who participate at the program training "How can we keep our physical and mental health despite the fact that stress is like a rollercoaster?".

The first researcher of the physiological consequences of stress has been Hans Selye. The concept of occupational stress first came up in 1976 [2].

Stress is the body's reaction to a mentally or emotionally disruptive or upsetting condition. Over the course of time, various studies [3] show that stress has become a major problem, for example: Study no.l.

A remarkable study is related in the documentary "Stress: Portrait of a Killer"[4] released in 2008 by National Geographic. The case refers to the colony of baboons studied R. Sapolsky in which an unexpected event occurred. Eldest head of the baboons consumed food remaining from the people who passed through the area and all other males situated hierarchical superior and the most aggressive did the same. These baboons were contracted tuberculosis and died. The colony remained only with females and males that were lower ranked. Robert S. has regretted the death of baboons, but this tragic event has led to a new research.

In the ten years that followed, the colony became extremely sociable and quiet. Past events (fight and other conflicts) that had caused stress disappeared. Researcher Robert Sapolsky confesses that his work doesn't make him free of stress, but he feels pleasure and this gives him an advantage.

Professor M. Marmot argues the same thing - it is particularly important to keep away stress by finding a job where we feel comfortable, we feel valued and our work is rewarded accordingly. 
The conclusion of these studies can be translated as a question: "Are we able to learn from the colony of baboons and the event that caused the change from an aggressive and hierarchical society to a one equal and calm without strong social events?".

Study no.2. Essential research papers were mentioned by Kelly McGonigal in her TED Talks speech, "How To Make Stress Your Friend"[5].

In this study, over 30.000 adults in the U.S.A. were monitored over a period of eight years, and it started out by asking people questions such as: "How stressed out have you felt during the past year?", "Do you think stress is harmful to your health?" Research carried out on the matter showed that people who had been very stressed during the previous year were at a $43 \%$ higher risk of mortality, but this was only true for those who were convinced that stress was damaging their health. The very stressed ones, but who did not see stress as harmful, were not more exposed; on the contrary, they were at the lowest risk of mortality, even when compared to the less stressed ones.

During the eight years, 182.000 Americans died prematurely, not because of stress, but because of their belief that stress was harmful. Approximately 20.000 deaths/year occurred due to the belief that stress was harmful.

Last year's 15th major cause of death in the U.S.A. was the belief that stress is harmful, thus killing more people than AIDS, skin cancer and homicide. Science says that changing our perception over stress would make us healthier.

Kelly McGonigal claims that those who attend lectures on stress would be able to remember fragments from the lectures when under a lot of stress. An example of such a fragment would be: "This is my body helping me rise to this challenge". When stress is perceived this way, the body perceives this distinction and its response to stress becomes a much healthier one.

In my opinion the stress it is our body's response to life's challenge, both real and imagined. In this domain of occupational stress management any reserch and any step made in this huge labyrinth called "stress" matters!

\section{Measurement results}

This present case study is the result of a one-month experience of stress management training delivered to a group of 30 employees.

In order to verify the validity of the hypotheses and to achieve the goals that had been set, the following tool was used:

- The Cohen Williamson Questionnaire, to identify the level of stress (Fig.1).

Cohen Scoring: each item is rated on a 5-point scale ranging from never (0) to almost always (4). Positively worded items are reverse scored, and the ratings are summed, with higher scores indicating more perceived stress.

Cohen questionnaire scores are obtained by reversing the scores on the four positive items. For example, $0=4,1=3,2=2$, etc. and then summing across all 10 items. Items $4,5,7$, and 8 are the positively stated items.

Individual scores on the Cohen questionnaire can range from 0 to 40 with higher scores indicating higher perceived stress.

- Scores ranging from 0-14 would be considered low/ without stress.

- Scores ranging from 14-20 would be considered moderate stress.

- Scores ranging over 20 would be considered high perceived stress.

The questions in this scale ask about your feelings and thoughts during the last month. In each case, you will be asked to indicate how often you felt or thought a certain way. Although some of the questions are similar, there are differences between them and you should treat each one as a separate question. The best approach is to answer fairly quickly [1]. 


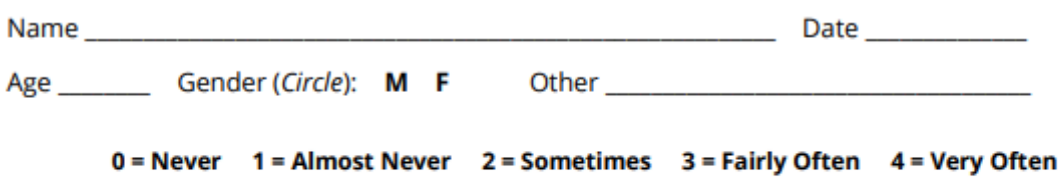

1. In the last month, how often have you been upset because of something that happened unexpectedly?

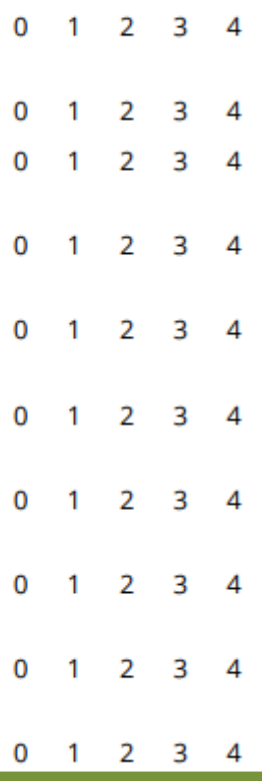

$$
\begin{array}{lllll}
0 & 1 & 2 & 3 & 4 \\
0 & 1 & 2 & 3 & 4 \\
0 & 1 & 2 & 3 & 4
\end{array}
$$$$
\begin{array}{lllll}
0 & 1 & 2 & 3 & 4
\end{array}
$$

2. In the last month, how often have you felt that you were unable to control the important things in your life?

3. In the last month, how often have you felt nervous and "stressed"?

4. In the last month, how often have you felt confident about your ability to handle your personal problems?

5. In the last month, how often have you felt that things were going your way?

6. In the last month, how often have you found that you could not cope with all the things that you had to do?

7. In the last month, how often have you been able to control irritations in your life?

8. In the last month, how often have you felt that you were on top of things? things that were outside of your control?

Figure.1. Cohen questionnaire

\section{Interpretation of measurement results}

In the current study, there were 30 respondents to the questionnaires. The research took place at the end of month of May 2018 and the respondents are employees of several companies in Bucharest. For the present study, the statistic indicators can be found below (Table.1).

Table 1. Data pertaining to the Cohen questionnaire

\begin{tabular}{|c|c|c|}
\hline Respondent & Score $\mathbf{X}_{\mathbf{i}}$ & $\mathbf{X}_{\mathbf{i}}^{\mathbf{2}}$ \\
\hline $\mathbf{1}$ & 14 & 196 \\
\hline $\mathbf{2}$ & 14 & 196 \\
\hline $\mathbf{3}$ & 30 & 900 \\
\hline $\mathbf{4}$ & 15 & 225 \\
\hline $\mathbf{5}$ & 8 & 64 \\
\hline $\mathbf{6}$ & 11 & 121 \\
\hline $\mathbf{7}$ & 11 & 121 \\
\hline $\mathbf{8}$ & 10 & 100 \\
\hline $\mathbf{9}$ & 15 & 225 \\
\hline $\mathbf{1 0}$ & 11 & 121 \\
\hline $\mathbf{1 1}$ & 21 & 441 \\
\hline $\mathbf{1 2}$ & 10 & 100 \\
\hline $\mathbf{1 3}$ & 10 & 64 \\
\hline $\mathbf{1 4}$ & 8 & 64 \\
\hline $\mathbf{1 5}$ & 20 & 400 \\
\hline
\end{tabular}




\begin{tabular}{|c|c|c|}
\hline Respondent & Score $\mathbf{X}_{\mathbf{i}}$ & $\mathbf{X}_{\mathbf{i}}^{\mathbf{2}}$ \\
\hline $\mathbf{1 6}$ & 20 & 400 \\
\hline $\mathbf{1 7}$ & 18 & 324 \\
\hline $\mathbf{1 8}$ & 18 & 324 \\
\hline $\mathbf{1 9}$ & 12 & 144 \\
\hline $\mathbf{2 0}$ & 21 & 441 \\
\hline $\mathbf{2 1}$ & 19 & 361 \\
\hline $\mathbf{2 2}$ & 15 & 225 \\
\hline $\mathbf{2 3}$ & 19 & 361 \\
\hline $\mathbf{2 4}$ & 19 & 361 \\
\hline $\mathbf{2 5}$ & 15 & 225 \\
\hline $\mathbf{2 6}$ & 25 & 625 \\
\hline $\mathbf{2 7}$ & 23 & 529 \\
\hline $\mathbf{2 8}$ & 7 & 49 \\
\hline $\mathbf{2 9}$ & 18 & 324 \\
\hline $\mathbf{3 0}$ & 25 & 625 \\
\hline$\sum=30$ & $\sum=\mathbf{4 8 2}$ & $\sum=\mathbf{8 . 6 5 6}$ \\
\hline & & \\
\hline
\end{tabular}

The average for the group of 30 respondents was 16,06 points. According to the answers quota, after a program training "How can we keep our physical and mental health despite the fact that stress is like a rollercoaster?", results show that the group are not under heavy stress.

Out of the 30 respondents, a number of 11 people (approx. $36 \%$ ) had obtain scored ranging from 14-20 which means that they are under stress. A number of 8 people (approx.26\%) had obtain scored higher than 20 points, thus falling in the category of people under heavy stress. The other 11 people respondents (approx. 36\%) scored less than 14 points, therefore falling outside the category of people under heavy stress.

Average $=\frac{\sum_{i=1}^{30}{\text { Interview } \text { results }_{i}}_{30}}{30}=\frac{482}{30}=16,06$

Percentage of respondents with stress $=\frac{11}{30}=0,36$

Percentage of respondents under heavy stress $=\frac{8}{30}=0,26$

Percentage of respondents who are not under heavy stress $=\frac{11}{30}=$ $=0,366(6) \approx 0,36$

The chart for Cohen questionnaire is presented below, in figure.2. 
Volume 1, Issue 1, 2019

ISSN: 2668-0416

Thoth Publishing House

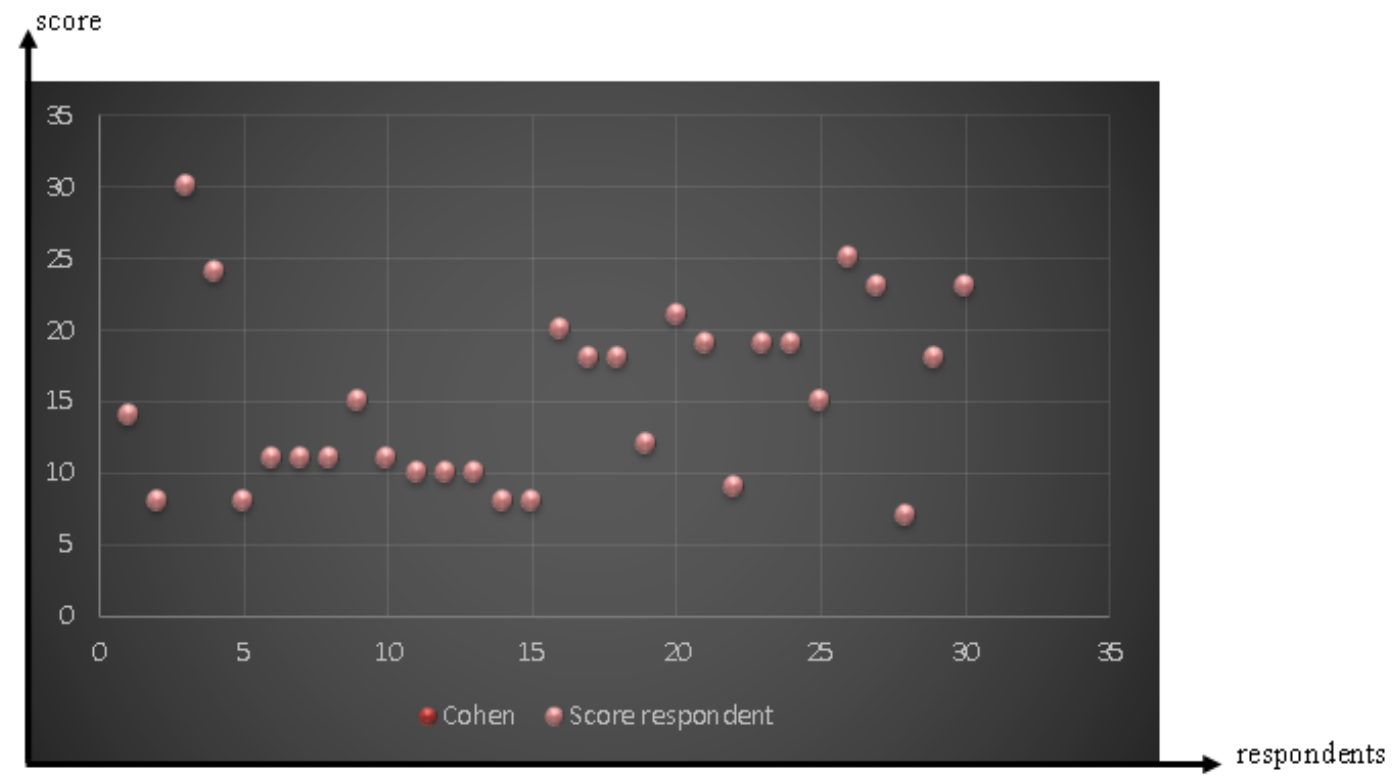

Figure 2. Cohen questionnaire results chart

Representation of the average associated with the Cohen Questionnaire is presented below, in figure.3.

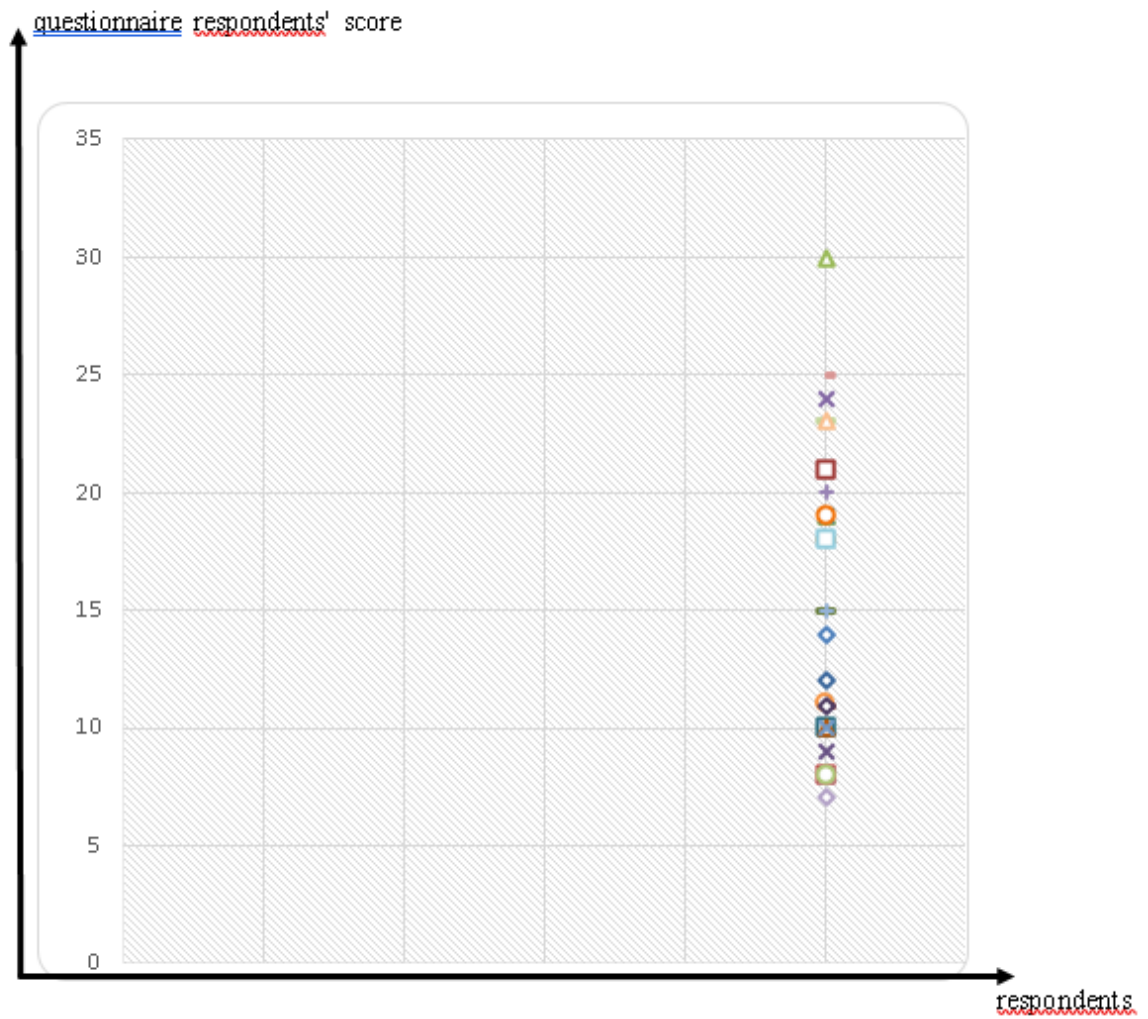

Figure 3. Representation of the average associated with the Cohen Questionnaire 
The main occupational-stress-related costs (figure.4) that a company is faced with are: costs caused by the absence of the employees from the work place due to stress-related issues, costs generated by the recruitment and training of new employees, costs caused by disturbances in the production flow, medical costs and so one [6].

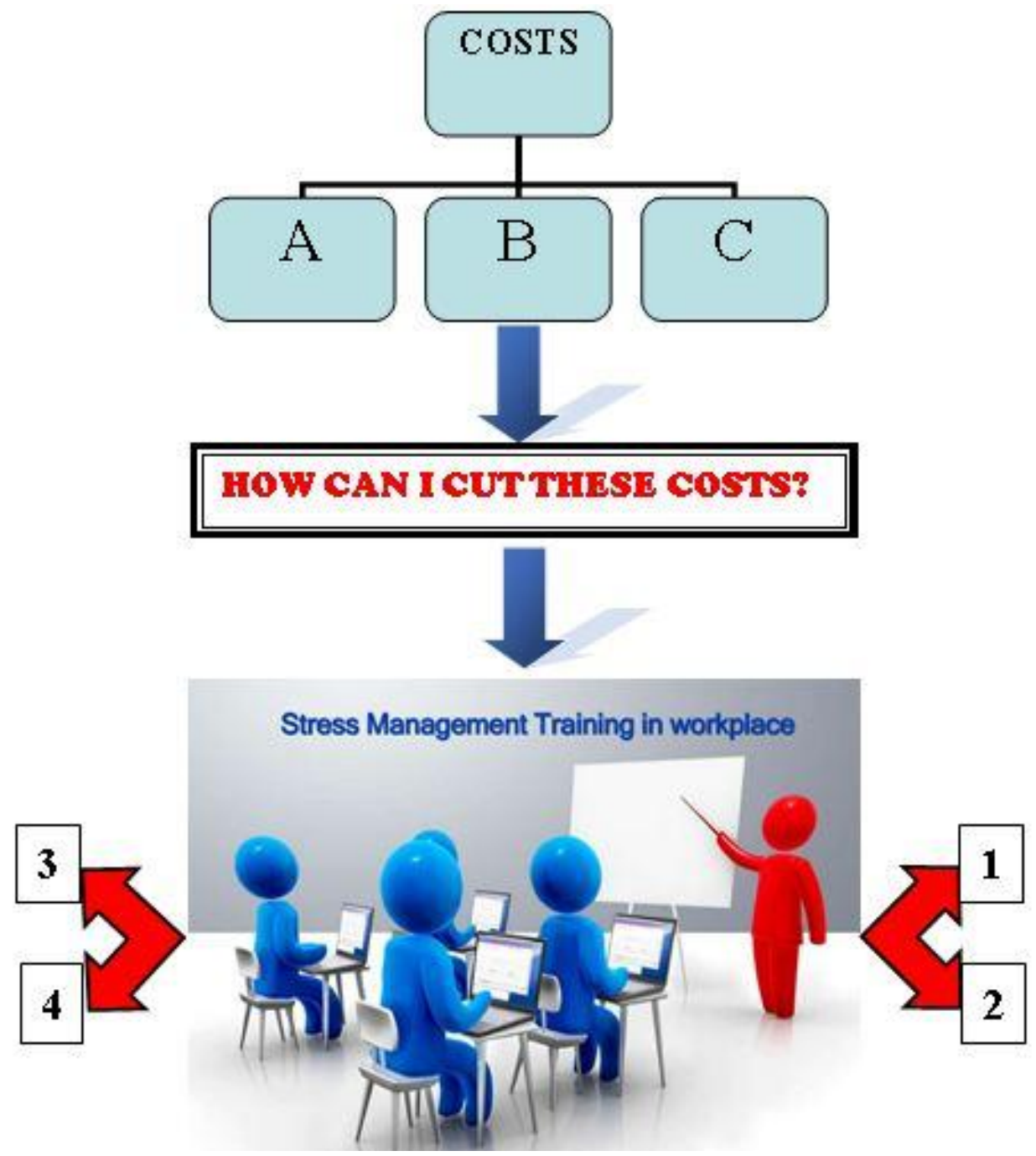

Figure.4. Occupational-stress-related costs and training program

The legend for figure 4 it is presented below:

A- Expenses for managing health and safety at work;

B- Costs caused by the absence of the employees from the work place due to stress-related issues;

C- Costs generated by the recruitment and training of new employees;

1- Increase in productivity by reducing the amount of sick leaves;

2- Decrease in health service expenses;

3- Increase in professional motivation among employees;

4- Introducing trainings on organizational stress management for better awareness of the damage that stress can cause.

This Stress Management training program it is a work-life balance with benefits for company like: improved customer satisfaction, better team communications and morale, reduced negative organizational stress, retention of valued employees, increased individual productivity and 
responsibility, reduction of medical expenses in companies, Health and safety at work through the elimination of major financial losses caused by absenteeism, medical expenses, and the decrease in productivity at work and so on.

Other benefits are related with the individual: increased productivity, balance and happiness every day, reduced personal stress, improved time management with family and friends.

The course overview (figure.5) related to the "How can we keep our physical and mental health despite the fact that stress is like a rollercoaster?" it is below:

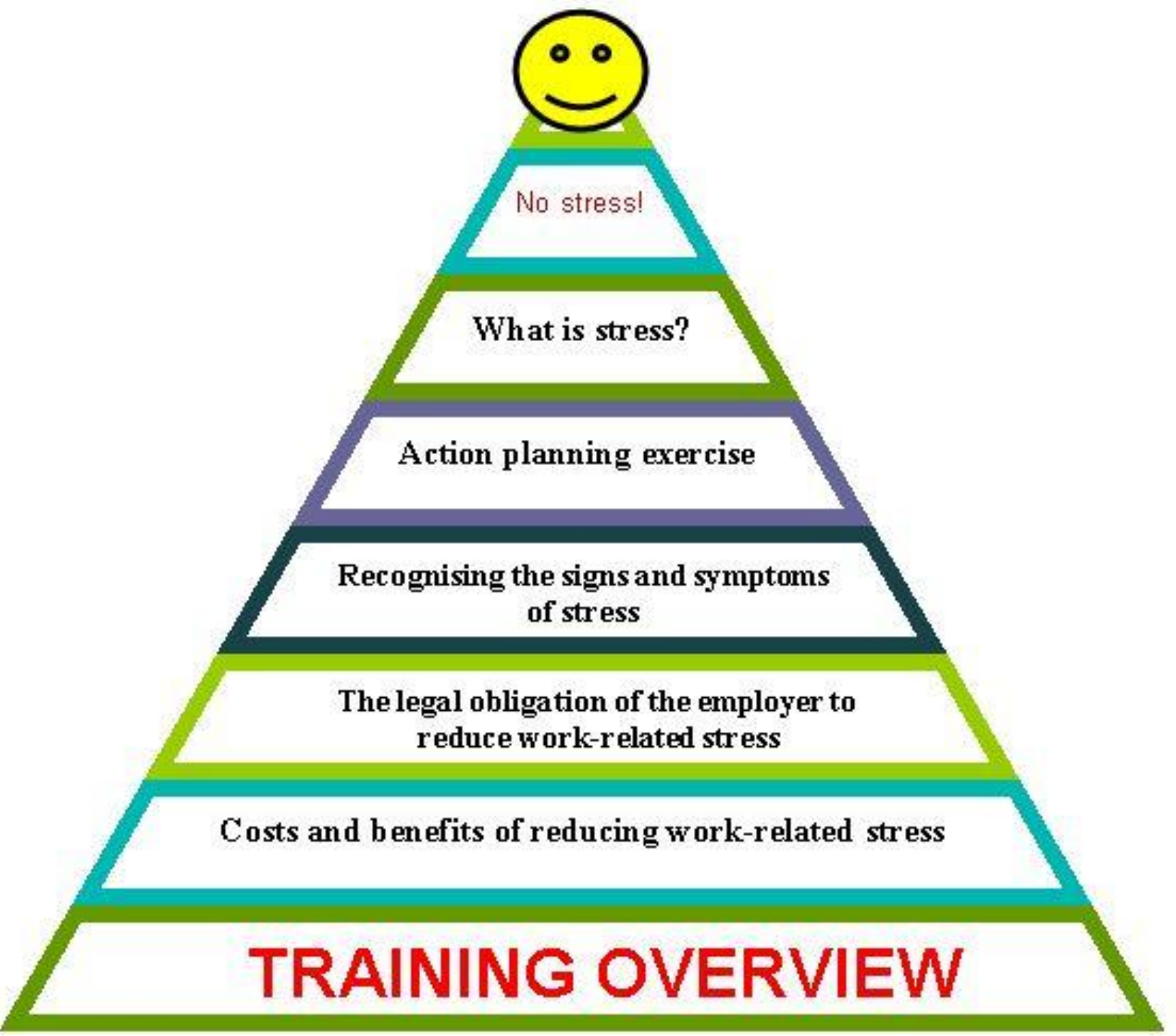

Figure.5. Training overview

I consider that the results in the field of stress control are visible and introduction of trainings on organizational stress management for better awareness of the damage that stress can cause it is a good ideea.

\section{Conclusions}

The conclusions of the case study are that the information received in training programs truly helps people to manage stress and this confirms the need to implement training programs in all the companies. The key to reducing distress is providing to people information about what to expect and about the general concept of stress management. 
In this study there were 30 respondents from several environment in Romania, who took part in this study. In that which concerns gender, out of the total amount of respondents, 18 of them were males and 12 were females. The stress level among the people of this study was found without stress with $36 \%$.

I personally consider that one of the steps towards decreasing stress levels would be ensuring staff training in management of occupational stress.

\section{References}

[1] Khalili R, Sirati Nir M, Ebadi A, Tavallai A, Habibi M, Validity and reliability of the Cohen 10item Perceived Stress Scale in patients with chronic headache: Persian version Asian J Psychiatr 2017 Apr;26:136-140

[2] Cosa E L, The Role of Psychological Mediators In Emotional Distress In School Teachers. The Impact of Personal Development Interventions Doctor's degree thesis Cluj-Napoca 2011

[3] Dascălu L C, Research of the influence of organisational stress levels over the economiv efficciency in integrated management systems Doctoral thesis September 2015 Bucharest Romania

[4] *** https://articles.mercola.com/sites/articles/archive/2014/07/05/stress-effects.aspx.

[5] $\quad * * *$ http://www.ted.com/talks/kelly_mcgonigal_how_to_make_stress_your_friend.

[6] Niţu L, Solomon Gh, Model for Conformity Assesment of Integrate Management Systems UPB Scientific Bulletin Seria D 2012 Bucharest Romania 